\title{
Os Determinantes dos Gastos em P\&D no Brasil: Uma Análise com Dados em Painel
}

\author{
Juan Jensen \\ Naércio Menezes-Filho \\ Roberto Sbragia
}

\author{
Universidade de São Paulo \\ Universidade de São Paulo \\ Universidade de São Paulo
}

\section{RESUMO}

O objetivo deste texto é investigar os principais determinantes dos gastos em P\&D no Brasil. Utilizamos neste trabalho a base de dados da ANPEI sobre indicadores de capacitação e inovação tecnológica no Brasil, abrangendo o período de 1994 a 1998. Conciliamos esta base de dados com várias técnicas econométricas, visando garantir robustez aos resultados. Os resultados encontrados mostram que os gastos em $P \& D$ se comportam como um random walk, e que firmas maiores gastam menos em P\&D como proporção do seu faturamento bruto. Nas equações para os determinantes de P\&D, o investimento em capital físico é a variável mais importante, indicando uma forma de complementaridade entre os dois tipos de investimento. Finalmente, a margem de lucro líquida parece não ter influência nos gastos em $P \& D$, que parece ser um investimento de mais longo prazo.

\section{PALAVRAS-CHAVE}

P\&D, inovações, ANPEI, produtividade

ABSTRACT

This paper aims at examining the determinants of R\&D expenditures in Brazil. We use a new database (from ANPEI) with firm level information on R\&D and other technological expenditures from 1994 to 1998, and several econometric techniques. The results show that $R \& D$ expenditures follow a random walk and that larger firms spend proportionally less in $R \& D$. The main determinant of R\&D seems to be investments in physical capital, which indicates some form of complementarity between the two types of investment. Finally, profitability does not seem to be an important determinant of R\&D expenditures in Brazil, suggesting that long-term determinants are more important.

KEY WORDS

P\&D, innovations, ANPEI, productivity

JEL Classification

032 


\section{INTRODUÇÃO}

A inovação tecnológica é um dos principais determinantes do desenvolvimento socioeconômico dos países. (JONES \& WILLIANS, 1999). Países que possuem programas de inovação tecnológica normalmente são nações mais ricas, possuem um parque industrial mais avançado e têm menos desigualdade social. Mas o que é inovação tecnológica? Segundo Schumpeter (1934), um dos primeiros economistas a estudar o assunto, inovação tecnológica é a implementação de novos produtos ou processos, ou também mudanças significativas em produtos ou processos já existentes.

Um dos principais fatores a influenciar ativamente o processo de inovação tecnológica são os gastos em pesquisa e desenvolvimento (P\&D). Segundo o manual Frascati ${ }^{1}$ da OECD, P\&D compreende o trabalho criativo realizado em uma base sistemática com a finalidade de aumentar o estoque de conhecimento existente, incluindo conhecimento científico e tecnológico, assim como o uso desse conhecimento para novas aplicações. O termo P\&D abrange, então, três atividades: 1) Pesquisa Básica: trabalho experimental ou teórico com a finalidade de compreender fenômenos e fatos observáveis, mas sem uma aplicação particular; 2) Pesquisa Aplicada: investigação original com o intuito de adquirir novos conhecimentos direcionados a um objetivo prático; 3) Desenvolvimento Experimental: aplicação do conhecimento já adquirido com a finalidade de desenvolver novos materiais, produtos, processos, sistemas e serviços ou de melhorar os já existentes.

Uma comparação de gastos em P\&D como porcentagem do PIB entre países pode ser vista na Tabela 1 (adaptado de ANDREASSI, 2000), na qual se constata que o Brasil gasta menos que as naçóes mais desenvolvidas. O Brasil gastou, em 1996, 1,22\% do PIB em P\&D, enquanto que Japão, EUA e Alemanha gastaram $2,94 \%, 2,54 \%$ e $2,81 \%$, respectivamente. A tabela também traz informaçôes acerca dos gastos como porcentagem do PIB divididos entre a parte oriunda das empresas e a parte relativa ao governo. Podemos observar que, para o caso brasileiro, o investimento em P\&D é pe-

1 Manual da OECD de 1993, que descreve as principais definiçốes e convenções para medidas de P\&D. 
queno por parte das empresas, e não por parte do governo, que possui um padrão de gastos similar ao de nações mais desenvolvidas.

TABELA 1 - COMPARAÇÕES INTERNACIONAIS DE DISPÊNDIOS EM P\&D PARA O ANO DE 1997

\begin{tabular}{lccc}
\hline Países & $\%$ PIB & $\begin{array}{c}\text { \% PIB gasto pelas } \\
\text { Empresas }\end{array}$ & $\begin{array}{c}\text { \% do PIB gasto } \\
\text { pelo Governo }\end{array}$ \\
\hline Japão (1) & 2,94 & 1,94 & 1,00 \\
EUA & 2,54 & 1,80 & 0,74 \\
Alemanha & 2,81 & 1,86 & 0,95 \\
Canadá & 1,47 & 0,81 & 0,66 \\
Itália & 1,21 & 0,70 & 0,51 \\
Espanha & 0,84 & 0,41 & 0,43 \\
Brasil (2) & 1,22 & 0,39 & 0,83 \\
\hline
\end{tabular}

(1) Dados de 1993; (2) Dados de 1996, divulgados pelo Ministério da Ciência e Tecnologia.

É inquestionável a importância que os gastos em P\&D possuem nos países mais ricos e desenvolvidos. Podemos ver os resultados desse maior esforço inovador em um parque industrial mais avançado, na geração constante de novos produtos e processos e também na própria tecnologia de ponta desenvolvida e utilizada por esses países.

No Brasil, a importância do desenvolvimento da infra-estrutura tecnológica como suporte à atividade produtiva tornou-se mais visível a partir da década de noventa, com a abertura comercial, momento em que o País optou pelo modelo de inserção competitiva no comércio mundial. Se comparadas com as empresas estrangeiras, as brasileiras investem pouco em $\mathrm{P} \& \mathrm{D}$, como visto na Tabela 1. Isso se deve, em parte, à falta de estabilidade econômica que reinou por muito tempo no Brasil, dificultando o planejamento de longo prazo, como é o caso do investimento em P\&D. O pequeno grau de abertura da economia, que no passado protegia nossas indústrias da competição externa, também influenciou negativamente o processo de geração de inova- 
ções tecnológicas. Esta situação, vivida em um passado recente, vem se modificando gradativamente com a abertura comercial da década de noventa e com a estabilização macroeconômica a partir de 1994.

Existem muitos trabalhos aplicados envolvendo gastos em P\&D para países mais desenvolvidos, mas apesar do tema ser de extrema importância, existe pouca coisa aplicada ao Brasil. Entre os motivos da pequena quantidade de trabalhos para o Brasil podemos destacar a baixa qualidade dos dados, que apresentam muitos erros de mensuração e não possuem uma freqüência temporal satisfatória.

Este trabalho tentará mostrar empiricamente quais são os determinantes dos gastos em P\&D para firmas brasileiras, comparando-o com os determinantes dos investimentos em capital físico. Conciliamos técnicas econométricas recentes com uma nova base de dados para firmas brasileiras, a base de dados da ANPEI (Associação Nacional de P,D\&E das Empresas Inovadoras), que inclui firmas de várias regiões, subsetores industriais, porte e origem de capital. Acreditamos que a importância deste trabalho esteja em contribuir para a compreensão da inovação tecnológica no ambiente brasileiro, entendendo as diferenças deste tipo de investimento com os investimentos de capital físico. Na conjuntura econômica atual os investimentos em P\&D, passam a ser de extrema importância e é desejável entender um pouco mais sobre a sua dinâmica.

O trabalho está organizado em cinco partes, além desta breve introdução. A primeira parte apresenta uma revisão da literatura de trabalhos aplicados a gastos em P\&D. A segunda parte compreende a descrição das técnicas econométricas que foram utilizadas em nossas regressões. A descrição da base de dados a ser utilizada nessas regressões está inserida na parte três. Os resultados de nossas regressões e a análise de resultados estão na quarta parte. A última parte conclui, indicando algumas limitações do trabalho. 


\section{REVISÃO DA LITERATURA}

A literatura sobre investimento em P\&D é vasta, e talvez o primeiro autor a explorar a importância de investimentos em inovação tecnológica seja Schumpeter no início do século XX. Nesta seção veremos principalmente trabalhos que estejam, de alguma forma, relacionados à aplicação de métodos econométricos para determinar as relações de investimento em capital físico e investimentos em P\&D. Estamos interessados em trabalhos que utilizem dados microeconômicos no nível das firmas, dada a natureza dos dados utilizados e pelas vantagens relacionadas a este tipo de dados.

Lach e Schankerman (1989) exploram empiricamente a interação dinâmica entre P\&D, investimento de capital e performance no mercado de ações para firmas americanas no setor científico envolvendo o período de 1973 a 1981. Os resultados empíricos encontrados pelos autores foram de que o investimento é determinado por dois fatores: um deles afeta os gastos em P\&D e decisões de investimento em capital físico; o outro é basicamente não relacionado com a atividade de P\&D. Uma variação nos fatores comuns, que afeta os dois tipos de investimento, tem um impacto imediato em gastos em P\&D e um grande impacto, mas defasado, em investimento de capital físico, sendo uma de suas características seu impacto permanente. Já uma variação nos outros tipos de fatores tem um efeito imediato em investimento de capital físico, sem ter impacto em P\&D, e com a característica de se dissipar rapidamente ao longo dos anos. Portanto, os autores concluem que as forças que causam mudanças de longo prazo nos programas de investimento são basicamente as mesmas que determinam os gastos em P\&D. Flutuações anuais em investimento não têm muita relação com atividades de P\&D.

Hall (1992) fez um estudo empírico com um painel de firmas americanas do setor de manufaturados abrangendo o período de 1973 a 1987. O autor encontrou evidências de que o fluxo de caixa é o fator predominante influenciando investimento em capital físico e em P\&D. Fluxo de caixa é mais importante que outras variáveis como vendas, dívidas ou Q de Tobin, apesar de haver correlação contemporânea entre todas essas variáveis. Hall também encontrou evidências de que os problemas de liquidez importam mais 
para investimentos em capital físico do que para investimentos em P\&D, mas que aumento no lucro esperado está relacionado com aumento nos dois tipos de investimento.

Himmelberg e Petersen (1994) procuraram mostrar a relação entre investimento em P\&D e investimento em capital físico no que se refere a financiamento interno. Utilizam pequenas firmas no setor high-tech dos Estados Unidos no período de 1983 a 1987. Um dos principais objetivos do trabalho, segundo os autores, é mostrar que os gastos em P\&D são determinados por financiamento interno, pois "since Schumpeter, economist have argued that internal finance is an important determinant of R\&D investment." (p. 38). Mas apesar da importância deste tipo de financiamento para estimular atividades de $\mathrm{P} \& \mathrm{D}$, os estudos empíricos em trabalhos anteriores, quase sem exceção, não encontraram essa relação. A importância deste tipo de financiamento se deve basicamente a dois motivos, segundo Kamien e Schwartz (1978): primeiramente, porque financiamento externo em atividades de P\&D é difícil de ser obtido, pelo simples motivo de este tipo de investimento náo possuir colateral, ou seja, muitas vezes a firma que quer efetuar o empréstimo não possui bens suficientes para ceder como garantia ao empréstimo caso o investimento não gere retorno; em segundo lugar, porque as firmas não estão interessadas em revelar seus segredos, em detalhes, para obter esses empréstimos, com medo de perder a idéia para um rival. Utilizando dados anuais e regressões contemporâneas, Himmelberg e Petersen concluem que P\&D e investimento em capital físico são sensíveis ao fluxo de caixa, sendo este resultado robusto a várias especificaçôes econométricas para dados em painel. Encontraram também que a magnitude do coeficiente estimado é sensível à especificação econométrica. Os autores discutem ao final que os resultados, diferentes dos obtidos em outros estudos, podem ter sido influenciados pela característica das firmas do setor high-tech, que enfrentam maiores problemas de restrição de crédito, devendo então financiar seus investimentos com recursos próprios, principalmente investimentos em P\&D.

Bond e Van Reenen (1999) fazem um levantamento cuidadoso da literatura da aplicação de métodos econométricos para estudar decisões de investimento (inclusive investimentos em P\&D) e emprego, utilizando dados microeconômicos em nível da firma. Segundo os autores, dados microeco- 
nômicos oferecem importantes vantagens no estudo do comportamento do investimento e do emprego. Entre estas vantagens destacam: a eliminação do impacto da agregação, a variação nas variáveis explicativas ajudando a identificar os parâmetros de interesse e a vantagem de poder estudar o comportamento heterogêneo entre as diferentes firmas. A utilização de dados microeconômicos também apresenta alguns problemas, pois muitas vezes esses dados não são representativos, e também são limitados na quantidade de informação. Segundo os autores, uma grande proporção do investimento das firmas se dá em ativos intangíveis, sendo o P\&D um dos mais importantes. Destacam também que a maioria dos trabalhos econométricos focou-se nos efeitos do P\&D, em medidas de performance das firmas, e que existe um movimento recente em entender os determinantes de P\&D, principalmente a relação entre restrição orçamentária e gastos em P\&D. A maioria dos trabalhos nesse sentido diz respeito à relação entre fluxo de caixa $\mathrm{e}$ P\&D, e segundo Bond e Van Reenen a incerteza sobre o retorno do investimento em P\&D, a falta de colateral e o perigo de perder a idéia para um rival os levam a acreditar que a firma utilizará recursos próprios para financiar gastos em P\&D. Por outro lado, os altos custos de ajustamento dos investimentos em P\&D não permitem que choques transitórios nos fluxos de caixa tenham um impacto em decisões de P\&D. Exatamente por isso as firmas somente investirão em P\&D se estiverem certas de não encontrar problemas de restrição orçamentária.

Bond, Harhoff e Van Reenen (1999) testam a importância do fluxo de caixa em investimento em capital físico e investimento em P\&D utilizando dados de firmas alemãs e britânicas. Os autores procuram responder se restriçóes de crédito são importantes na determinação dos investimentos e se o impacto é diferente em investimentos em capital físico com relação a investimentos em P\&D. Argumentam também que alguns tipos de investimentos são mais vulneráveis à restrição de crédito, entre eles os investimentos em ativos intangíveis, pois estes apresentam mais riscos e normalmente não possuem colateral. Afirmam ainda que alguns poucos autores sugerem que P\&D são sensíveis ao fluxo de caixa, mas que os resultados apresentados são fracos. Como gastos em P\&D possuem muitos custos de ajustamento, sugerem que restrições a crédito talvez se manifestem na decisão de fazer ou não P\&D, e não nas decisões de quanto gastar anualmente. Os autores estimam 
um modelo para investimento em capital físico, elaborando um modelo similar para gastos em P\&D. A estimação foi feita utilizando regressões pelo método GMM e o resultado encontrado foi que fluxo de caixa não é importante na determinação de investimento ou P\&D para firmas alemãs. Já para firmas britânicas, fluxo de caixa é informativo para investimento em capital físico, mas não para P\&D. Apesar disto, fluxo de caixa prevê quais firmas farão P\&D e quais não. Os autores analisam este resultado sugerindo que restrições a crédito são maiores na Grã-Bretanha, e que as firmas que fazem P\&D naquele país devem constituir um grupo selecionado, onde a restrição a crédito deve se apresentar em menor grau.

Klette e Griliches (2000) desenvolvem um modelo teórico com firmas heterogêneas dentro de uma mesma indústria, onde investimentos em P\&D e inovações estocásticas são os motores do crescimento das firmas. Os autores criticam os estudos econométricos de investimento em $\mathrm{P} \& \mathrm{D}$, pois estes são baseados em modelos econométricos sem muito conteúdo teórico. O modelo teórico desenvolvido no trabalho em questão é consistente com três regularidades empíricas muito estudadas, a saber: 1) a intensidade de P\&D é independente do tamanho da firma; 2) o crescimento da firma é independente de seu tamanho; e 3) a distribuição do tamanho das firmas é altamente assimétrico. O trabalho traz também resultados empíricos derivados de uma amostra de firmas norueguesas do setor high-tech. Entre os resultados encontrados para essa amostra os autores confirmam os pontos acima, ou seja: 1) a intensidade de P\&D é independente do tamanho da firma; estudos de outros autores encontram uma variação proporcional (ver COHEN \& KLEPPER, 1996 e BOUND, 1984); 2) o crescimento da firma é independente do tamanho da firma; 3) a distribuição do tamanho das firmas é assimétrica. A partir do modelo também é derivado que gastos em P\&D se comportam como um passeio aleatório, mas os autores não encontram exatamente essa relação na amostra de firmas norueguesas, sendo o resultado encontrado, como os próprios autores definem, próximo a um passeio aleatório.

Nos quadros a seguir é apresentado um resumo das variáveis que afetam gastos em P\&D (Quadro 1) e investimento em capital físico (Quadro 2) para os trabalhos citados neste breve resumo da literatura. Limitamo-nos 
aos trabalhos que trataram de identificar os determinantes de P\&D e de investimentos de capital.

QUADRO I - DETERMINANTES DE PEOD

\begin{tabular}{llcc}
\hline Autores & Base de & \multicolumn{2}{c}{ P\&D } \\
\cline { 3 - 4 } & dados & Fluxo de Caixa & Vendas \\
\hline Hall (1992) & EUA & SIM & SIM \\
Himmelberg e Petersen (1994) & EUA & SIM & NÃO \\
Bond, Harhoff e Van Reenen (1999) & Grã-Bretanha & NÃO & SIM \\
Bond, Harhoff e Van Reenen (1999) & Alemanha & NÃO & SIM \\
\hline
\end{tabular}

QUADRO 2 - DETERMINANTES DE INVESTIMENTO EM CAPITAL FÍSICO

\begin{tabular}{llcc}
\hline Autores & Base de & \multicolumn{2}{c}{ Investimento de Capital } \\
\cline { 3 - 4 } & dados & Fluxo de Caixa & Vendas \\
\hline Hall (1992) & EUA & SIM & SIM \\
Himmelberg e Petersen (1994) & EUA & SIM & SIM \\
Bond, Harhoff e Van Reenen (1999) & Grã-Bretanha & SIM & SIM \\
Bond, Harhoff e Van Reenen (1999) & Alemanha & NÃO & SIM \\
\hline
\end{tabular}

\section{ESTATÍSTICA DESCRITIVA}

Conforme antes afirmado, a base de dados utilizada neste trabalho é a da ANPEI (Associação Nacional de P,D\&E das Empresas Inovadoras), que disponibiliza indicadores empresariais de capacitação e inovação tecnológica. Esta base contém informações coletadas anualmente, por meio de um informe padronizado, entre as empresas brasileiras desde 1994 (referente ao ano de 1993), incluindo firmas de várias regiões, subsetores industriais, por- 
te e origem de capital em um painel não balanceado. Ao todo participam da base cerca de 1.500 empresas, numa média de 420 empresas por ano, com uma representatividade, em termos de faturamento, de aproximadamente $42 \%$ do PIB industrial brasileiro para o ano de 1998. A base de dados da ANPEI é considerada desde 1997, pelo Ministério da Ciência e Tecnologia, como fonte oficial para informaçôes sobre indicadores de inovação tecnológica do setor empresarial.

As variáveis da base da ANPEI que iremos utilizar neste trabalho são: patrimônio líquido, faturamento bruto, lucro líquido depois de descontado o imposto de renda, investimentos de capital e gastos em P\&D. Para a formação da variável gastos em P\&D utilizamos a soma das variáveis despesas com $\mathrm{P} \& \mathrm{D}$, despesas com serviços tecnológicos e despesas com engenharia não rotineira. Despesas com P\&D incluem gastos com salários e encargos sociais, depreciação de investimentos e demais despesas necessárias, como matéria-prima, comunicação e transporte. Despesas com serviços tecnológicos compreendem as atividades que dão suporte à execução dos trabalhos em P\&D. Despesas com engenharia não rotineira compreendem gastos com atividades de engenharia diretamente relacionada ao processo de inovação, envolvendo o desenvolvimento de produtos ou processos, incluindo atividades como design, métodos e padrões de trabalho e rearranjos de planta.

Para a formação da amostra que iremos trabalhar retiramos as observações que, a partir dos dados originais, claramente continham erros de medida. Os erros mais comuns e graves nesta primeira triagem foram: faturamento bruto negativo, patrimônio líquido negativo e lucro líquido muito alto em relação ao faturamento bruto. Retirando esses casos, restou uma amostra com firmas que possuem as características constantes da coluna (1) da Tabela 2. Os gastos médios em P\&D dessas firmas se situaram em 2.2 milhões de dólares por ano, no período de 1994 a 1998, sendo o investimento de capital da ordem de US\$ 27.9 milhões. O faturamento bruto foi, em média, de 205 milhões de dólares, sendo de 13.7 milhões de dólares o lucro líquido. $\mathrm{O}$ patrimônio líquido médio foi de 256 milhões de dólares. O número de observações variou de 1.603, para gastos em P\&D, a 2.290, para faturamento bruto. A tabela também traz informações sobre o desvio padrão das variáveis. 
TABELA 2 - CARACTERÍSTICAS DA AMOSTRA, MÉDIAS ANUAIS POR EMPRESA (MILHÕES DE US\$)

\begin{tabular}{lcccc}
\hline & $(1)$ & $(2)$ & $(3)$ & $(4)$ \\
\hline Gastos em P\&D & 2.2 & 2.3 & 3.1 & 4.5 \\
& 12.4 & 13.8 & 17.0 & 22.3 \\
N & 1603 & 1140 & 714 & 400 \\
Invest. em Capital & 27.9 & 28.6 & 42.7 & 69.8 \\
& 184 & 193 & 245 & 352 \\
N & 1715 & 1554 & 942 & 400 \\
Faturamento Bruto & 205 & 244 & 352 & 577 \\
& 1170 & 1320 & 1670 & 2480 \\
N & 2290 & 1554 & 942 & 400 \\
Lucro Líquido & 13.7 & 14.7 & 22.4 & 39.2 \\
& 116.0 & 86.5 & 109.0 & 156.0 \\
N & 2026 & 1554 & 942 & 400 \\
Patrimônio Líquido & 256 & 274 & 396 & 645 \\
& 1540 & 1440 & 1770 & 2450 \\
N & 2170 & 1554 & 942 & 400 \\
\hline
\end{tabular}

Nota: Desvios padrões em itálico.

$\mathrm{Na}$ segunda coluna encontram-se as características da subamostra com firmas que reportaram as quatro variáveis que potencialmente determinam gastos em P\&D. O número de observações com P\&D caiu para 1.140, enquanto que para as outras variáveis existem 1.554 observações. Qualitativamente, quando é feita esta restrição na amostra, as características das firmas não variam muito em relação à primeira coluna. Assim, gastos em $\mathrm{P} \& \mathrm{D}$ passam de 2.2 milhões de dólares para 2.3 milhões, em média. As médias das outras variáveis também variam pouco: os investimentos de capital foram da ordem de US\$ 28.6 milhões, faturamento bruto de 244 milhões de 
dólares (esta foi a maior variação, atingindo 14\%), lucro líquido de 14.7 milhões e patrimônio líquido de 274 milhões.

A restrição para a coluna (3) foi obter uma subamostra em que as empresas reportaram as variáveis por pelo menos dois anos consecutivos. Podemos claramente perceber um aumento significativo nas médias amostrais para todas as variáveis, refletindo possivelmente um aumento do tamanho médio das firmas. Na média, os gastos em P\&D foram da ordem de 3.1 milhões de dólares, o investimento em capital físico foi de 42.7 milhões, o faturamento bruto 352 milhões, o lucro líquido 22.4 milhões e o patrimônio líquido 396 milhões. O aumento do valor médio das variáveis em relação às médias da amostra da coluna (2) situou-se em aproximadamente $45 \%$.

Na coluna (4) temos a subamostra final, a que será usada na maioria das regressões da próxima seção. Esta subamostra contém firmas com pelo menos 3 observações consecutivas e que tenham reportado as cinco variáveis. Esta amostra compreende 400 observações e um total de 103 firmas. Novamente encontramos um aumento do tamanho médio das firmas (na média, as variáveis cresceram $62 \%$ em relação à coluna (3)), aumentando também a dispersão das observações, medida pelo desvio padrão. Os gastos em P\&D situaram-se em 4.5 milhões e os investimentos de capital em 69.8 milhões. O faturamento bruto de nossa subamostra final foi de 577 milhões, sendo 39.2 milhões o lucro líquido. O patrimônio bruto no período foi de 645 milhões.

Um ponto interessante a observar é que apesar da subamostra final eliminar firmas pequenas, aumentando o tamanho médio das firmas, as relações entre as variáveis (relações de proporcionalidade) se mantêm mais estáveis. Medindo as variáveis com relação ao faturamento bruto, e comparando a amostra inicial com a final, vemos que gastos em P\&D variam de $1.1 \%$ a $0.8 \%$ do faturamento bruto. A variável investimento de capital varia de $13.6 \%$ a $12.1 \%$; o lucro líquido de $6.7 \%$ a $6.8 \%$ e o patrimônio líquido de $125 \%$ a $112 \%$. Uma comparação mais detalhada entre as amostras pode ser vista na Tabela 3. 
TABELA 3 - VARIÁVEIS COMO PORCENTAGEM DO FATURAMENTO BRUTO

\begin{tabular}{lcccc}
\hline & $(1)$ & $(2)$ & $(3)$ & $(4)$ \\
\hline Gastos em P\&D & $1.1 \%$ & $1.0 \%$ & $0.9 \%$ & $0.8 \%$ \\
Investimentos em Capital & $13.6 \%$ & $11.7 \%$ & $12.1 \%$ & $12.1 \%$ \\
Lucro Líquido & $6.7 \%$ & $6.0 \%$ & $6.4 \%$ & $6.8 \%$ \\
Patrimônio Líquido & $125 \%$ & $112 \%$ & $113 \%$ & $112 \%$ \\
\hline
\end{tabular}

A Tabela 4 traz mais detalhes da amostra que será objeto de estudo na próxima seção. Nesta tabela podemos observar gastos em P\&D e investimentos de capital abertos em alguns subsetores. Os dados são valores médios por firma no período de 1994 a 1998. Observando a coluna de gastos de P\&D podemos destacar a Indústria de Metal Primário, com gastos médios de 17.9 milhões de dólares por firma, e o setor de Papel e Produtos de Papel, com 10.9 milhões por firma. Outros setores de destaque são Equipamentos Elétricos e Eletrônicos, e Químicos e Produtos Químicos, com 3.5 e 2.3 milhões de dólares, respectivamente. ${ }^{2}$

Examinando-se os gastos em investimento de capital verfica-se que praticamente os mesmos setores se sobressaem. O grande destaque são as Indústrias de Metal Primário, que possuem investimentos de 187.8 milhões de dólares, em média. Já as empresas do setor de Papel e Produtos de Papel apresentam investimentos médios de 80 milhões. Outros setores de destaque são: Alimentos, Químicos e Produtos Químicos e Equipamentos Elétricos e Eletrônicos, com 33.3, 28.1 e 15.2 milhões de dólares, respectivamente. $^{3}$

2 O setor agregado na última linha da tabela (outros) possui subsetores com apenas uma firma, e sua magnitude é alta (12.2 milhôes), pois o subsetor Extração e Refinação de Petróleo possui gastos muito altos, elevando então a média.

3 Novamente a média da agregação outros possui um valor alto e o subsetor responsável é mais uma vez Extração e Refinação de Petróleo, que faz com que a média atinja 329.1 milhões de dólares. 
Ao analisar a Tabela 4 podemos estar cometendo o erro de avaliar empresas grandes de um setor e compará-las com empresas pequenas de outro setor. Este problema é parcialmente resolvido se dividirmos nossas variáveis por faturamento bruto, que mede com bastante eficácia o tamanho das firmas.

TABELA 4 - GASTOS MÉDIOS ANUAIS DAS EMPRESAS POR SUBSETOR (EM US\$)

\begin{tabular}{lrrc}
\hline & Gastos em P\&D & $\begin{array}{r}\text { Investimentos } \\
\text { em capital }\end{array}$ & $\begin{array}{c}\text { Número de } \\
\text { observações }\end{array}$ \\
\hline Alimentos & 1.151 .491 & 33.337 .756 & 17 \\
Equipamentos de Medição & 85.076 & 83.308 & 15 \\
Equipamentos de Transportes & 1.511 .064 & 6.796 .919 & 20 \\
Equipamentos Elétricos e Eletrônicos & 3.467 .376 & 15.241 .881 & 48 \\
Indústrias de Metal Primário & 17.918 .872 & 187.840 .190 & 21 \\
Máquinas Industriais e Comerciais & 771.611 & 2.404 .727 & 64 \\
Papel e Produtos de Papel & 10.852 .965 & 80.002 .665 & 22 \\
Produtos de Borracha e Plástico & 1.596 .607 & 7.179 .704 & 27 \\
Produtos de Concreto e Vidro & 1.040 .344 & 6.336 .882 & 17 \\
Produtos de Metal (exceto máquinas) & 341.112 & 2.105 .663 & 16 \\
Químicos e Produtos Químicos & 2.269 .025 & 28.130 .171 & 78 \\
OUTROS & 12.231 .843 & 329.130 .210 & 55 \\
\hline
\end{tabular}

Analisando os gastos em P\&D, constantes da Tabela 5, a seguir, merecem destaque os setores de Papel e Produtos de Papel, que gastam, em média, $2.7 \%$ do faturamento bruto. Os setores de Máquinas Industriais e Comerciais e de Equipamentos de Transporte despendem, em média, 1.8\% do faturamento bruto. Outros setores de relevo são Indústrias de Metal Primário, com 1.4\%; Equipamentos Elétricos e Eletrônicos, com 1.1\%; e Equipamentos de Medição, também com 1.1\%. 
TABELA 5 - GASTOS MÉDIOS DAS EMPRESAS POR SUBSETOR COMO \% DO FATURAMENTO BRUTO

\begin{tabular}{lcc}
\hline & Gastos em P\&D & $\begin{array}{c}\text { Investimentos em } \\
\text { capital }\end{array}$ \\
\hline Alimentos & $0,1 \%$ & $3,7 \%$ \\
Papel e Produtos de Papel & $2,7 \%$ & $19,6 \%$ \\
Químicos e Produtos Químicos & $0,9 \%$ & $10,6 \%$ \\
Produtos de Borracha e Plástico & $0,9 \%$ & $4,1 \%$ \\
Produtos de Concreto e Vidro & $0,8 \%$ & $4,7 \%$ \\
Indústrias de Metal Primário & $1,4 \%$ & $14,2 \%$ \\
Produtos de Metal (exceto máquinas) & $0,5 \%$ & $2,9 \%$ \\
Máquinas Industriais e Comerciais & $1,8 \%$ & $5,5 \%$ \\
Equipamentos Elétricos e Eletrônicos & $1,1 \%$ & $4,8 \%$ \\
Equipamentos de Transportes & $1,8 \%$ & $8,2 \%$ \\
Equipamentos de Medição & $1,1 \%$ & $1,1 \%$ \\
OUtRos & $0,5 \%$ & $13,9 \%$ \\
\hline
\end{tabular}

Nesta tabela também podemos observar quais subsetores possuem mais gastos em investimento de capital em relação a faturamento bruto, e os destaques são Papel e Produtos de Papel, com investimentos de 19.6\% do faturamento bruto, Indústrias de Metal Primário, com 14.2\%, e Químicos e Produtos Químicos, com 10.6\%. Outros setores significativos são Equipamentos de Transporte com 8.2\% e Máquinas Industriais e Comerciais com $5.5 \%$.

Nesta seção procuramos mostrar como é distribuída a base da ANPEI, ressaltando algumas diferenças e restrições da amostra que será objeto de estudo. A principal diferença é que, aparentemente, a base utilizada contém firmas maiores. Mas, a princípio, a relação de proporcionalidade entre as variáveis não demonstrou muitas mudanças, aspecto que é bastante importan- 
te. Tentamos também mostrar algumas características desta subamostra final, destacando os subsetores que mais gastam em P\&D e em investimentos de capital, tanto no aspecto nominal quanto em relação ao tamanho, medido pelo faturamento bruto.

É importante atentar para o fato de que a base da ANPEI possui ainda muitos problemas, principalmente por ser uma base em formação. Os problemas aparecem particularmente nos primeiros anos de coleta dos dados, pois os funcionários selecionados para responder ao questionário nem sempre estavam capacitados para tal tarefa. Outro problema decorre da quantidade de informações não reportadas, seja por motivo estratégico ou pelo fato do funcionário ignorá-las. Um problema adicional é o fato de empresas não responderem ao questionário todos os anos, faltando, por conseguinte, informação de muitas empresas ao longo do tempo. Acreditamos que com o passar dos anos esta base de dados possa se tornar muito mais abrangente na quantidade de firmas e qualidade das informaçôes. Isto deve ocorrer naturalmente a partir do momento que as firmas se tornarem conscientes da importância que uma base como esta tem para o País.

\section{ANÁLISE DE RESULTADOS}

Nesta seção veremos como as firmas brasileiras se comportam no que diz respeito às relações de $\mathrm{P} \& \mathrm{D}$ e investimentos de capital. A base de dados é uma subamostra da base de dados da ANPEI, conforme descrito na seção 2 deste trabalho. Iniciaremos analisando os dados para os fatos estilizados, seguindo Klette e Griliches (2000). A seguir, utilizaremos uma das técnicas apresentadas no item 3.2 desta seção, faremos uma estimação por probit, se-

guida do cálculo das regressões de P\&D e investimento de capital físico, utilizando as outras técnicas citadas no item 3.2.

\subsection{Fatos Estilizados}

Analisaremos quatro pontos apontados por Klette e Griliches. Segundo os autores, existe uma regularidade empírica sobre a relação entre gastos em P\&D e faturamento bruto das firmas, qual seja: a intensidade de P\&D é in- 
dependente do tamanho da firma, medido por faturamento bruto. Para responder a esta questão calculamos uma regressão por MQO do log dos gastos em P\&D no log do faturamento bruto das firmas, onde o subscrito i representa cada firma e o subscrito t representa o ano. Utilizamos ainda dummies de ano, para controlar os efeitos macroeconômicos, e dummies de setor de atividade. Se esperarmos que essa relação seja proporcional, o parâmetro estimado deve ser próximo de um.

$$
\ln {\mathrm{P} \& \mathrm{D}_{\mathrm{i}, \mathrm{t}}}=0.6549 \text { In Faturamento }{ }_{\mathrm{i}, \mathrm{t}}+\text { dummies }+ \text { erro }
$$

Encontramos um parâmetro estimado de 0.6549, com um desvio padrão (entre parênteses) de $\mathbf{0 . 0 4 7 0}$. Por meio da estatística t, não podemos dizer que intensidade de P\&D é independente do tamanho da firma. O intervalo de confiança da estimativa do parâmetro a $95 \%$ é de [0.6037 a 0.7406 ]. Portanto, o resultado encontrado é que firmas maiores gastam em P\&D menos que proporcionalmente ao seu tamanho, resultado que é similar a outros estudos de P\&D feitos para o Brasil, como Sbragia (1999).

A segunda característica que vamos analisar é se crescimento da firma é independente do tamanho da firma. Calculamos uma regressão de log do faturamento bruto no log na própria variável defasada:

$$
\text { In } \text { Faturamento }_{\mathrm{i}, \mathrm{t}}=1.0037 \ln \text { Faturamento }_{\mathrm{i}, \mathrm{t}-\mathrm{l}}+\text { erro }
$$

e encontramos uma relação muito próxima a um random walk, mas estatisticamente podemos afirmar que firmas maiores crescem mais que firmas menores.

A terceira característica é a assimetria da distribuição do tamanho das firmas. Analisando a probabilidade de assimetria encontramos uma assimetria positiva com um valor $\mathrm{p}$ igual a 0.266 . Portanto, podemos dizer que a distribuição do tamanho das firmas é assimétrica e que a dispersão superior do tamanho das firmas é maior que a dispersão inferior. 
A quarta característica, de particular interesse para este trabalho, é que os gastos em P\&D se comportam como um passeio aleatório, ou seja, toda variação sucessiva em $y_{t}$ é gerada independentemente a partir de uma distribuição de probabilidade com média igual a zero, ou seja, $\mathrm{y}_{\mathrm{t}}$ é determinado por: $\mathrm{y}_{\mathrm{t}}=\mathrm{y}_{\mathrm{t}-\mathrm{l}}+\varepsilon_{\mathrm{t},} \operatorname{com} \mathrm{E}\left(\varepsilon_{\mathrm{t}}\right)=0$ e $\mathrm{E}\left(\varepsilon_{\mathrm{t}} \varepsilon_{\mathrm{s}}\right)=0$. A partir de nossa amostra, a regressão de $\log P \& D$ em $\log P \& D$ defasado gera o seguinte resultado:

$$
\ln \mathrm{P} \& \mathrm{D}_{\mathrm{i}, \mathrm{t}}=0.9869 \ln \mathrm{P} \& \mathrm{D}_{\mathrm{i}, \mathrm{t}-\mathrm{l}}+\text { erro }
$$

Encontramos um parâmetro estimado de 0.9869 , com um desvio padrão de 0.0100. Podemos, pois, afirmar, por meio do teste $t$, que o parâmetro não é estatisticamente diferente de um. O intervalo de confiança a 95\% é [0.9746 a 1.0071]. Portanto, gastos em P\&D se comportam como um passeio aleatório, ou seja, o melhor previsor para gastos de P\&D em um determinado ano é o gasto em P\&D no ano anterior.

\subsection{Resultados Econométricos}

Utilizaremos várias técnicas econométricas para determinar a relação entre gastos em P\&D e investimento em capital físico com as demais variáveis que potencialmente determinam o montante desses gastos. $\mathrm{O}$ uso de várias técnicas visa fortalecer a robustez dos resultados e corrigir possíveis problemas de viés e inconsistência que técnicas conceitualmente mais simples normalmente carregam. As técnicas utilizadas serão: MQO (Mínimos Quadrados Ordinários), Probit, Modelo de Seleção, Modelo de Efeitos Fixos e Modelo em Primeiras Diferenças. Uma descrição detalhada das técnicas utilizadas podem ser consultadas em Greene (1998). O modelo de seleção é mais apropriado que o de censura e truncagem, porque o modelo de censura supõe que problema é apenas de não-observabilidade dos valores de P\&D para as firmas que não os declaram (ou uma solução de canto), enquanto que o de truncagem é mais apropriado quando as variáveis explicativas, além da variável dependente, são não observadas. Neste caso, consideramos mais apropriado assumir que a declaração de gastos em P\&D é uma escolha (estratégica) por parte da firma, e que há uma correlação en- 
tre o termo aleatório da equação de participação e o termo da equação de volume de gastos.

\subsection{Probit}

As variáveis utilizadas na regressão por Probit e nas próximas regressões para gastos em P\&D e investimentos em capital físico estão em logaritmo. A única variável que não está em log é a variável lucro líquido. Como o lucro líquido de algumas empresas possui valor negativo, perderíamos informação ao trabalhar com esta variável em log. Preferimos então trabalhar com a variável lucro líquido dividido por faturamento bruto, pois, já que faturamento bruto é uma medida razoável de tamanho da firma, reduzimos dessa forma os problemas relacionados à escala.

A regressão de Probit procura examinar se existe alguma diferença entre as firmas que reportam gastos em P\&D positivos e as firmas que reportam gastos em P\&D igual a zero ou não reportam. Construímos então uma variável binária, que assume o valor 1 se a firma fez gastos de P\&D naquele ano, e assume o valor zero, caso ela não tenha feito gastos em P\&D ou não tenha reportado gastos em P\&D. A variável construída também assume $\mathrm{o}$ valor zero caso a empresa não tenha feito nenhum investimento em capital físico. A Tabela 6 mostra o resultado da regressão. Abaixo do respectivo coeficiente temos op-value.

As variáveis utilizadas nesta regressão foram llfat (lucro líquido dividido por faturamento bruto), lfat (log de faturamento bruto) e lpat (log de patrimônio líquido). Os parâmetros estimados com nível de significância a $5 \%$ são lfat (valor p igual a 0.001 ) e lpat (valor p igual a 0.040). Este resultado nos diz que quanto maior o faturamento bruto e quanto menor o patrimônio líquido, maior a probabilidade de a empresa fazer investimentos em P\&D e investimentos em capital físico. ${ }^{4}$

4 Uma regressão alternativa, sem considerar as observações das firmas que não reportaram gastos em $\mathrm{P} \& \mathrm{D}$, gera resultados bastante parecidos. Nesta regressão apenas o parâmetro associado à variável lfat é significativo, variando de 0,21 para 0,15 . Já o parâmetro associado à variável lpat deixa de ser significativo. 
TABELA 6 - MODELO PROBIT

\begin{tabular}{lc}
\hline Variáveis & Coeficiente \\
\hline Lucro/Faturamento & 0,350 \\
& 0.375 \\
Log(Faturamento) & 0,210 \\
& 0,001 \\
Log (Patrimônio) & $-0,104$ \\
& 0,043 \\
Dummies de Ano & Sim \\
Pseudo R & 0.068 \\
Observações & 942 \\
\hline
\end{tabular}

Nota: P-valor em Itálico.

Bond, Harhoff e Van Reenen (1999) realizam o mesmo tipo de exercício para uma base de dados de firmas britânicas e outra base de firmas alemãs. O resultado encontrado é que o tamanho da firma, medido por faturamento bruto em nossa regressão e por vendas na regressão dos autores citados acima, afeta positivamente a probabilidade de uma firma fazer gastos em P\&D na Grã-Bretanha e na Alemanha. Este mesmo resultado foi encontrado para a nossa base de firmas brasileiras. Os autores também utilizam a variável fluxo de caixa (lucro menos depreciação) na regressão e concluem que esta variável afeta positivamente a probabilidade de uma firma britânica fazer gastos em $\mathrm{P} \& D$, mas não possui qualquer relação com a probabilidade de uma firma alemã efetuar gastos em P\&D. Neste sentido, a amostra de firmas brasileiras parece se comportar como as firmas alemãs, pois a nossa medida de lucratividade não apresentou um parâmetro estimado significativo em nossa regressão, não influenciando, portanto, a probabilidade de uma firma efetuar gastos em P\&D. 


\subsection{Regressões de P\&D e Investimento}

\subsubsection{Determinantes de P\&D}

Partiremos agora para as regressóes utilizando gastos em P\&D como variável dependente. Os valores dos coeficientes estimados medem a elasticidade, e sua interpretação é: para cada $1 \%$ de aumento na variável dependente, aumenta-se em x\% (o valor do coeficiente estimado) os gastos em P\&D. A única variável a não medir elasticidade é a variável lucro líquido dividida por faturamento bruto (llfat), pois ela não se encontra em log. Utilizamos também dummies de ano em todas as regressões, pois estas variáveis controlam pelos efeitos macroeconômicos que afetam igualmente todas as firmas.

A primeira regressão, (coluna (1) da Tabela 7), relaciona log de gastos em P\&D com lucro líquido sobre faturamento bruto. O que se quer saber é se o lucro líquido daquele ano afeta os gastos com P\&D do mesmo ano. A resposta é não, pois com um valor p de 0.544 não rejeitamos a hipótese nula de que o parâmetro é igual a zero.

Na segunda regressão, coluna (2), incluímos também as variáveis de faturamento bruto (lpat), de patrimônio líquido (lfat) e de investimento em capital físico (linv). A estimação por MQO nos leva a concluir que duas variáveis são estimadas precisamente: Ifat (valor p igual a 0.000 ) mostra que o faturamento afeta positivamente os gastos em P\&D (para cada 1\% de aumento no faturamento, aumenta-se os gastos em P\&D em $0.4534 \%$ ); a outra variável é linv (valor p igual a 0.000 ), e para cada $1 \%$ de aumento no investimento há um aumento de $0.2025 \%$ em gastos de P\&D. 
TABELA 7 - OS DETERMINANTES DOS GASTOS EM P\&OD

\begin{tabular}{lccccc}
\hline $\begin{array}{l}\text { Variável Dependente: } \log \text { (Gastos } \\
\text { em P\&D) }\end{array}$ & $(1)$ & $(2)$ & $(3)$ & $(4)$ & $(5)$ \\
Técnica Utilizada & MQO & MQO & M. Sel. & EF & $1^{\text {a }} \mathrm{D}$. \\
\hline Lucro/Faturamento & 0.487 & 0.096 & 0.976 & 1.020 & 1.943 \\
& 0.544 & 0.897 & 0.246 & 0.482 & 0.089 \\
Log (Faturamento) & & 0.453 & 1.009 & 1.044 & 0.893 \\
& & 0.000 & 0.001 & 0.032 & 0.093 \\
Log (Patrimônio) & & -0.039 & -0.315 & -0.239 & -0.356 \\
& & 0.674 & 0.068 & 0.411 & 0.189 \\
Log (investimentos) & & 0.202 & 0.196 & 0.149 & 0.122 \\
& & 0.000 & 0.000 & 0.038 & 0.009 \\
Razão de Mills & & & 5.760 & 7.441 & 9.163 \\
& & & 0.073 & 0.042 & 0.039 \\
№ Observações & 400 & 400 & 400 & 400 & 297 \\
\hline
\end{tabular}

Abaixo de cada coeficiente estimado temos o p-value. As regressóes foram estimadas no Stata 6.0 de forma a apresentarem erros robustos.

Teste de significância conjunta dos efeitos fixos: $\mathrm{F}(102,88)=1,84$ p-valor $<0,01$.

Na terceira coluna pretendemos corrigir nossos resultados por um possível viés de seleção, incluindo uma nova variável, ou seja, a razão de Mills invertida, retirada de nossa estimação por Probit. A correção da amostra é necessária porque não estamos incluindo na regressão as firmas que não fizeram gastos em P\&D ou não reportaram a variável, ou ainda que não tenham feito investimentos de capital físico. Se, por essa razão, a nossa amostra não for aleatória, as regressões anteriores, regressões por $\mathrm{MQO}$, serão enviesadas e inconsistentes. Este problema é corrigido incluindo essa nova variável criada a partir do Probit, isto é, a razão de Mills invertida. Nesta nova regressão continuamos com lfat e linv como variáveis com parâmetros estimados significativos (valores de p iguais a 0.001 e 0.000 , respectivamente). É impor- 
tante notar que houve um grande aumento da importância do faturamento bruto na sua relação com gastos em P\&D após essa correção da amostra (de 0.4534 para 1.0099). Já a importância do investimento não mudou significativamente de magnitude. A razão de Mills invertida não é significante a $5 \%$, mas o é a $10 \%$, o que indica que possivelmente a nossa amostra de firmas que fazem P\&D não é uma amostra aleatória do conjunto de firmas com três observaçôes consecutivas.

A coluna (4) mostra a regressão por efeitos fixos. Este resultado é bastante interessante, pois este método, ao incluir uma dummy para cada firma, está eliminando tudo aquilo que é particular para cada firma, e que não varia no tempo. O teste de significância conjunta dos efeitos fixos rejeita a hipótese de eles serem conjuntamente iguais a zero. ${ }^{5}$ Apesar dos efeitos fixos serem significantes, os nossos resultados se mantêm, e continuamos com linv e lfat significativos (valor p igual a 0.038 e 0.032 , respectivamente). A magnitude do parâmetro associado ao investimento teve uma pequena redução, de 0.1962 para 0.1498. É interessante notar que a razão de Mills invertida, que controla o viés amostral, passou a ser significante a $5 \%$ (valor $\mathrm{p}$ igual a 0.042 ). Este resultado é importante porque demonstra que as regressões por MQO possuem viés de variável omitida quando não levamos em consideração os efeitos fixos.

A coluna (5) reporta os valores da regressão por primeiras diferenças. Este método também procura eliminar tudo aquilo que é constante para cada firma e que não varia ao longo do tempo, corrigindo também um possível viés de variável omitida. Um dos problemas enfrentados por este método é agravar erros de medida, pois como trabalhamos com as diferenças, qualquer variação por erro de mensuração terá muito mais impacto neste modelo que nos anteriores. Nas estimações encontramos a variável linv como significativa (valor $\mathrm{p}$ de 0.009 ) e a variável Mills (valor $\mathrm{p}$ de 0.039 ). A variável lfat não é mais significante a $5 \%$ (valor $\mathrm{p}$ de $\mathbf{0 . 0 9 3}$ ). Acreditamos que isto possa estar acontecendo justamente por erros de medida nas variáveis.

5 Estes estimadores são não-viesados sob hipóteses tradicionais, apesar de serem inconsitentes (ver WOOLDRIDGE, 2002, p. 273). 
Após as cinco diferentes estimações sobre os determinantes de gastos em P\&D para firmas brasileiras, parece claro que, das variáveis que estamos trabalhando, a única variável que influencia os gastos em P\&D, em todas as regressões, é o investimento em capital físico. Este resultado é de alguma forma similar ao encontrado por Lach e Schankerman (1989), que encontram evidências que gastos em P\&D variam com investimentos em capital físico de longo prazo, e por Toivanen e Stonemen (1998), que encontram uma relação de causalidade para firmas britânicas, onde investimento de capital prevê gastos em P\&D.

O faturamento bruto, apesar de não ser significativamente diferente de zero na última regressão, parece exercer alguma forma de impacto nos gastos em P\&D (a regressão por primeiras diferenças pode ter exacerbado erros de medida). Este resultado é similar ao encontrado por Bond, Harhoff e Van Reenen (1999) para os conjuntos de dados de firmas alemãs e britânicas, e Andreassi (2000), que em seu estudo para firmas brasileiras encontra uma alta correlação entre faturamento bruto e P\&D. Já Himmelberg e Petersen (1994) não encontram relação entre P\&D e faturamento bruto para o conjunto de firmas americanas do setor high-tech.

As outras variáveis, principalmente a variável lucro líquido sobre faturamento, parecem não ter nenhuma relação com gastos em P\&D. Então, podemos dizer, a princípio, que lucratividade não influencia nem a decisão e nem o montante de gastos em P\&D, resultado que é similar a alguns estudos sobre o tema, como o de Bond, Harhoff e Van Reenen (1999). Outros estudos encontram uma relação positiva entre gastos em P\&D e fluxo de caixa (lucro menos depreciação), como o de Hall (1992) e Himmelberg e Peterson (1994). Em seu estudo de firmas brasileiras, Andreassi (2000) também não encontra qualquer evidência de correlação de P\&D com lucro líquido.

\subsubsection{Determinantes de Investimento de Capital}

Para as regressões dos determinantes do investimento em capital físico utilizaremos as mesmas técnicas utilizadas nas regressões de P\&D, substituindo linv (log de investimento) por lpd (log de gastos em P\&D) entre os regressores. As regressões encontram-se na Tabela 8. 
Na primeira regressão, coluna (1), estimamos investimento de capital como função do lucro líquido sobre faturamento bruto, mas não encontramos esse parâmetro estatisticamente diferente de zero (valor p igual a 0.136).

A coluna (2) traz a regressão que inclui, além de lucro líquido, faturamento bruto, patrimônio líquido e gastos em P\&D. O resultado é que todos os parâmetros são significativamente diferentes de zero (valor p igual a 0.000 para lfat e lpat e lpd e de 0.030 para llfat). Ou seja, estimando nossa regressão por $\mathrm{MQO}$, temos a impressão de que todas as variáveis afetam positivamente os investimentos de capital. Mas, como descrito na seção 2, podemos estar cometendo vários tipos de erros nesta estimação, resultando em parâmetros enviesados e inconsistentes.

A coluna (3) traz o modelo de seleção, no qual incluímos a razão de Mills invertida para corrigir algum problema de viés na amostra. Com esta correção obtivemos mudança de magnitude de alguns parâmetros. A variável lpat deixou de ser significativa a $5 \%$, mas continua a $10 \%$, e a variável Mills, que corrige o possível viés, não é significativa, indicando que não existem problemas de não aleatoriedade de nossa amostra (os valores p são de 0.000 para lfat e lpd; 0.008 para llfat; 0.068 para lpat e 0.123 para Mills).

Um resultado interessante é obtido na quarta regressão, coluna (4), onde utilizamos efeitos fixos. Quando eliminamos tudo o que é constante e/ou específico para cada firma, corrigindo um provável viés de variável omitida, as variáveis de faturamento bruto e de patrimônio líquido passam a ser não significantes. É importante observar que o teste de efeitos fixos também rejeita a hipótese de eles serem conjuntamente iguais a zero. Nesta estimação as variáveis que continuam sendo significantes são llfat (valor $\mathrm{p}$ igual a 0.016), indicando algum problema de restrição de crédito, ou seja, que a firma investe mais em capital físico quando tem lucros maiores, e lpd (valor $\mathrm{p}$ igual a 0.038), que poderia indicar alguma relação de complementaridade ou de causalidade entre investimentos e gastos em P\&D.

A coluna (5), que traz a estimação por primeiras diferenças, mostra exatamente o mesmo resultado obtido por efeitos fixos. Ou seja, eliminando algum problema de viés de variável omitida, as variáveis significantes são llfat 
e lpd (valor p igual a 0.006 e 0.004 respectivamente), reforçando a conclusão da regressão por efeitos fixos. A diferença de magnitude dos parâmetros estimados entre a estimação por efeitos fixos e a estimação por primeiras diferenças é muito pequena.

TABELA 8 - OS DETERMINANTES DO INVESTIMENTO EM CAPITAL FÍSICO

\begin{tabular}{lccccc}
\hline Variável Dependente: linv & $(1)$ & $(2)$ & $(3)$ & $(4)$ & $(5)$ \\
Técnica Utilizada & MQO & MQO & M. Sel. & EF & $1^{\mathrm{a}} \mathrm{D}$. \\
\hline Lucro/Faturamento & 1.890 & 1.247 & 1.794 & 2.833 & 2.789 \\
& 0.136 & 0.030 & 0.008 & 0.016 & 0.006 \\
Log (Faturamento) & & 0.530 & 0.8785 & 0.297 & 0.308 \\
& & 0.000 & 0.000 & 0.455 & 0.366 \\
Log (Patrimônio) & & 0.414 & 0.2400 & 0.070 & 0.109 \\
& & 0.000 & 0.068 & 0.767 & 0.587 \\
Log (Gastos em P\&D) & & 0.159 & 0.1554 & 0.099 & 0.089 \\
& & 0.000 & 0.000 & 0.038 & 0.004 \\
Razão de Mills & & & 3.604 & 1.047 & 2.711 \\
& & & 0.123 & 0.726 & 0.276 \\
№ Observações & 400 & 400 & 400 & 400 & 297 \\
\hline
\end{tabular}

Abaixo de cada coeficiente estimado temos o p-value. As regressóes foram estimadas no Stata 6.0 de forma a apresentarem erros robustos.

Teste de significância conjunta dos efeitos fixos: $\mathrm{F}(102,88)=2,74$ p-valor $<0,01$.

Após as cinco regressões de investimento de capital físico como variável dependente, chegamos à conclusão de que a variável lucro líquido sobre faturamento bruto afeta o investimento positivamente. Parece então haver algum problema de restrição de crédito para firmas brasileiras, pois as firmas investem mais quando o lucro líquido aumenta em relação ao faturamento bruto, resultado que se adapta bem para o contexto do mercado brasileiro. Este resultado também é reportado por vários autores na literatura interna- 
cional, como Hall (1992), que encontra esta relação para firmas americanas do setor de manufaturados, Himmelberg e Peterson (1994), onde esta relação aparece para firmas do setor high tech americano, e Bond Harhoff e Van Reenen (1999), que encontram esta relação para firmas britânicas, mas não para firmas alemãs, e justificam o resultado dizendo que firmas britânicas estão sujeitas a restrição de crédito, o que não acontece com as firmas alemãs, que não mostram evidências claras deste tipo de problema.

A outra variável que mostra uma elasticidade positiva com os gastos em investimentos são os gastos em $P \& D$. Isto pode indicar alguma relação de complementaridade ou de causalidade entre as duas variáveis.

Comparando os resultados dos determinantes de gastos em P\&D com os determinantes de investimento em capital físico, parece claro que a restrição de crédito está muito mais presente em investimentos físicos. Os investimentos em P\&D não variam com a variação nos lucros, provavelmente porque a atividade de P\&D necessita de aporte constante de capital, não podendo sofrer variações bruscas. Um resultado que corrobora esta evidência é que, conforme vimos, gastos em P\&D se comportam como um randow walk.

\section{CONCLUSÃO}

Este trabalho teve como motivação a importância de gastos em P\&D para firmas brasileiras na atual conjuntura nacional e internacional, dada a influência cada vez maior que este tipo de investimento exerce num mundo globalizado. Procuramos identificar quais os principais determinantes de gastos em P\&D, comparando os resultados com os determinantes de investimentos em capital físico. Utilizamos neste trabalho a base de dados da ANPEI sobre indicadores de capacitação e inovação tecnológica no Brasil, abrangendo o período de 1994 a 1998. Conciliamos esta base de dados com várias técnicas econométricas visando garantir robustez aos resultados.

Os resultados encontrados foram que gastos em P\&D se comportam como um random walk, tendo poucas variações ao longo do tempo, resultado que 
se encontra no modelo teórico de Klette and Griliches (2000). Também encontramos evidências de que firmas maiores gastam menos em P\&D proporcionalmente ao seu faturamento bruto. Na estimação por Probit o resultado foi que quanto maior a firma, tamanho medido por faturamento bruto, e quanto menor o patrimônio líquido, maior a probabilidade da firma se engajar em atividades de P\&D. A variável lucro não apresentou relação com a probabilidade de uma firma fazer ou não gastos em P\&D.

Nas equações para os determinantes de P\&D vimos que o investimento em capital físico é a variável mais importante, indicando talvez alguma forma de complementaridade ou causalidade entre os dois tipos de investimento. Outra variável que parece ter incidência na atividade de P\&D é o faturamento bruto, influenciando não só a probabilidade de uma firma efetuar gastos em P\&D, como também a magnitude destes gastos, resultado similar ao encontrado por Andreassi (2000) para o Brasil. Um resultado interessante é a não influência de lucro na atividade de P\&D, corroborando a hipótese de que flutuações anuais nos lucros da empresa não devem acarretar variações nos gastos em P\&D, que é um investimento de longo prazo. Este resultado é similar ao encontrado por Bond, Harhoff e Van Reenen (1999) e Andreassi (2000), mas oposto ao encontrado por Hall (1992) e Himmelberg e Peter$\operatorname{sen}(1994)$.

Quando analisamos investimento em capital físico como variável dependente, encontramos como resultado que a variável lucro líquido dividido por faturamento bruto determina o investimento. Acreditamos que o resultado encontrado se deva à existência de alguma restrição de crédito para as empresas brasileiras, o que é, de fato, uma situação bastante real para o nosso contexto, caracterizada por condições pouco atraentes para empréstimos. Resultado idêntico é encontrado por Hall (1992), Himmelberg e Petersen (1994), e parcialmente por Bond, Harhoff e Van Reenen (1999). Outra variável que mostra uma elasticidade positiva com os gastos em investimentos são os gastos em P\&D, podendo indicar alguma relação de complementaridade entre as duas variáveis.

Um resultado muito importante é obtido quando incluímos em nossas regressões os efeitos fixos nas equações dos determinantes de investimento de 
capital físico, controlando nossas regressões para tudo o que é especifico e constante ao longo do tempo para cada uma das firmas da amostra. Ao controlar por esses fatores, os parâmetros estimados associados às variáveis faturamento bruto e patrimônio líquido passam a ser não significantes.

Uma das limitações deste estudo é que não pudemos ser totalmente fiéis à literatura sobre o tema, pois a base de dados não fornece algumas variáveis importantes, como estoque de capital e estoque de P\&D (medida de conhecimento). No entanto, esperamos que os resultados contribuam adicionando novas informações sobre este campo do conhecimento que é carente de trabalhos aplicados ao Brasil. Sabemos que não é possível generalizar os resultados encontrados, porque deve haver viés de seleção em nossa amostra, dado que as firmas que respondem o questionário da ANPEI são provavelmente bastante diferentes daquelas que não respondem.

Uma pergunta mais geral, que pode ser tema de em um trabalho futuro, é por que firmas brasileiras investem menos em P\&D quando comparadas com firmas americanas. Esta resposta pode ser importante no sentido de guiar políticas industriais, dada a alta correlação entre gastos em P\&D e crescimento de um país.

\section{BIBLIOGRAFIA}

ANDREASSI, T. Estudo das velações entre indicadores de PEDD e indicadores de resultado empresarial em empresas brasileiras. 2000. Tese (Doutorado), Faculdade de Economia, Administração e Contabilidade da USP.

ANPEI. Indicadores empresariais de inovação tecnológica - Resultados da base de dados da ANPEI. São Paulo: ANPEI, n. 8, 1999.

ARELLANO, M.; BOND, S. R. Dynamic panel data estimation using DPD98 for Gauss. University of Oxford, 1998. Mimeografado.

BOND, Stephen; REENEN, John Van. Microeconometric models of investment and employment. The Institute for Fiscal Studies, 1999. Mimeografado.

BOND, Stephen; HARHOFF, Dietmar; REENEN, John Van. Investment, R\&D and finacial constraints in Britain and Germany. The Institute for Fiscal Studies, Working Paper Series n. W99/5, 1999. 
BOUND, J.; CUMMINS, C.; GRILICHES, Z.; HALL, B.; JAFFE, A. Who does R\&D and who patents. In: GRILICHES, Z. (ed.), ReD, patents and productivity. Chicago: University of Chicago Press, 1984.

COHEN, W. M.; KLEPER, S. A reprise of size and R\&D. The Economic Journal, n. 106, p. 925-951, 1996.

GREENE, W. H. Econometric analysis. Third edition. Macmillan Publishing Company, 1998.

HALL, B. H.; GRILICHES, Z.; HAUSMAN, J. A. Patents and R and D: is there a lag? International Economic Review, v. 27, n. 2, p. 265$283,1986$.

HALL, B. H. Investment and research and development at the firm level: does the source of financing matter? NBER Working Papers Series, $\mathrm{n}$. 4096, 1992.

HIMMELBERG, Charles P.; PETERSEN, Bruce C. R\&D and internal finance: a panel study of small firms in high-tech industries. Review of Economics, n. 76, p. 38-51, 1994.

JENSEN, J.; MENEZES FILHO, N.; SBRAGIA, R. Determinantes da intensidade de P\&D na indústria brasileira: algumas evidências empíricas. Boletim INOVA n. 26, 2001.

JONES, C. I.; WILLIANS, J. C. Too much of a good thing? The economics of investment in R\&D. NBER Working Paper Series, $\mathrm{n}$. $7283,1999$.

KAPLAN, Steven; ZINGALES, Luigi. Do investment cash flow sensitivities provide useful measures of financing constraints. Quarterly Journal of Economics CXII, 1, p. 169-216, 1997.

KAMIEM, M. I.; SCHWARTZ, N. L. Self-financing of an R\&D project. American Economic Review, v. 68, n. 3, p. 252-261, 1978.

KLETTE, Tor Jakob; GLILICHES, Zvi. Empirical patterns of firm growth and R\&D investment: a quality ladder model interpretation. The Economic Joumal, 110, p. 363-387, 2000.

LACH, Saul; SCHANKERMAN, Mark. Dynamics of R\&D and investment in the scientific sector. Journal of Political Economy, n. 97, p. 880-904, 1989.

LOPES, C. V. Restrição a crédito e investimento: evidência de painel. 2001. Dissertação (Mestrado), FGV-EPGE, Rio de Janeiro.

MAIRESSE, Jacques; HALL, Bronwyn. Estimating the productivity of research and development: an exploration of GMM methods using data on French and United States manufacturing firms. NBER Working Papers Series, n. 5501, 1996. 
OECD. Main definitions and conventions for the measurment os research and experimental development (ReD) - A summary of the Frascati manual 1993. Paris, 1994.

SBRAGIA, Roberto. Los indicadores de I, D\&E en las empresas mas y menos innovadoras. Spacios, Revista Venezuelana de Gestion Tecnologica, v. 120, n. 1, 1999.

SCHUMPETER, J. A. The theory of economic development. New York: Oxford University Press, 1961.

TERRA, Cristina T. Finance and changing trade patterns in Brazil. Ensaios Econômicos. EPGE, n. 354, Setembro, 1999.

TOIVANEM, O.; STONEMEN, P. Dynamics of R\&D and investment: UK evidence. Economic Letters, 1998. 